\title{
Historical cetology
}

The Natural History of the Whale. By L. Harrison Matthews. Pp. 219. (Weidenfeld and Nicolson: London, 1978.) $£ 12.50$.

The World Naturalist Series (not to be confused with the New Naturalist Series) continues with a book on whales by the editor of the series. There are nine chapters-on Cetology from its Beginnings, Cetacean Diversity, Food and Feeding, Breeding and Growth, Swimming and Diving, Migration, Communication and Echolocation, Behaviour and Social Relations, Parasites, Diseases and Enemies-followed by a list of living species, a bibliography and index.

The book is very readable and is especially strong on the historical aspects of research on whales. Unlike so many subjects where the older literature tends to become obsolete, modern cetology depends very much on the earlier work. One of the reasons for this lies, alas, in the appalling overexploitation of whales, so that many species are protected and some may be near extinction. Thus, material, often available in the past only through the whaling industry, is no longer obtainable. The discoveries made have been impressive, especially when one considers the difficulty of handling such large specimens, the problem of rapid decomposition before they can be dissected and the need, often, to play 'second fiddle' to the whale-catchers. Much of the more recent discoveries on whale physiology and behaviour come from the smaller cetaceans such as the dolphins which are fairly easy to catch and keep in captivity. The building of oceanaria has also made it possible to watch and train larger cetaceans such as the Killer Whale. Speculation about echolocation, feeding habits, buoyancy mechanisms and the problems of deep diving have come from the study of so-called functional anatomy.

This all makes fascinating reading. Everything is on a massive or record scale. The blue whale is the largest living animal; whales make migrations of 28,000-30,000 kilometres and can 'sprint' at 20 knots; sperm whales can dive to 3,000 feet and become entangled in submarine cables; the Antarctic whales in their heyday ate 150 million tons of krill annually; some whales have tape-worms which are 50 feet long!

I found the style of the book rather uneven. The author expects a fairly high standard of knowledge from the reader when discussing some of the anatomy, especially that of the skull, yet elsewhere, for example, he discusses the genetic code, DNA and the philosophy of immortality (pages 76 and 137). In general the diagrams, though clear, are inadequately labelled and have no scale given. There are 16 pages of black-and-white plates which cannot fail to fascinate the reader. One aerial photograph of a school of white whales in the Canadian Arctic showing adults and calves is especially interesting.

The author is decidedly acerbic about some of his predecessors and of some later investigators. On page 28 he gives very short shrift to Nessiteras rhombopteryx P. Scott (1975) the "non-animal of Loch Ness" (reported in Nature 258, 466, 1975). On page 101 he castigates the owners of pets who recycled whale meat as dog-droppings on city pavements. $\mathrm{He}$ is rightly uncompromising in his criticism of anthropomorphism in our interpretation of cetacean behaviour. For example, the explanation of the apparent saving of

\section{J. H. S. Blaxter}

human swimmers in distress by dolphins lifting them to the surface almost certainly lies in the lifting of newly-born calves by their mothers to the surface for their first breath of air. Other instances of relationships between cetaceans and man such as the riding of ships' bow-waves can easily be explained as advantageous to the animal, which saves energy as it utilises the bow-wave to push itself along. Although the author is not in possession of the results of naval research on the use of dolphins for underwater warfare, he thinks their intelligence has been overestimated and their potential is limited. If dolphins were really intelligent would they not take every opportunity "to pull a human swimmer in difficulties down to death" considering that man has been a ruthless destroyer of dolphins for centuries?

Dr Harrison Matthews' book is quite different in style from two recent books on sea mammals reviewed in Nature (270, 641, 1977). It deals only with cetaceans and in greater detail. I would rate it as reading for any biologist or well-informed laymen.

J. H. S. Blaxter is Senior Principal Scientific Officer at the Dunstaffnage Marine Research Laboratory, Oban, Argyll, UK.

\section{Summary of rheological activity}

Mechanics of Non-Newtonian Fluids. By W. R. Schowalter. Pp. 300. (Pergamon: Oxford, 1978.) £17.50.

This text, directed toward graduate students and others beginning research in rheology, begins with a fine motivational chapter 1 and then launches into a five-chapter development of mathematical and physical foundations in terms of tensor analysis. This segment, rigorous but rather dry for students, would require elaboration by an instructor to be fully successful.

The following three chapters are designed to describe rheometric and related flows; Noll's simple-fluid concept is used throughout. Chapter 7 introduces the idea of viscometric flows and provides several illustrations. The equations of continuity and motion for incompressible fluids, in the three major coordinate systems, are appended. Measurements of the viscometric functions are described in chapter 8 , in which numerous flows are studied: plane and cylindrical Couette flow, axial motion in open and annular tubes, jet methods (jet swell, thrust on tube), and the Jackson-Kaye elevated cone procedure. A survey of experimental difficulties is given separately, including end effects, viscous heating, and hole error. Chapter 9 emphasises stretch-history concepts, specialising to extensional flow and perturbations from viscometric flows.

Model-building is encountered in chapters 10 and 11 . Elementary models - purely viscous, generalised Newtonian, and linear viscoelastic (differential and integral) fluids-are found in chapter 10. For the first time molecular concepts are introduced, through the dilute-solution polymer dynamics theory of Zimm. The latter treatment is 